\title{
The Analysis of Verbless Sentences
}

\author{
Yasir Hameed Alotaibi ${ }^{1}$ \\ ${ }^{1}$ The Department of Arabic Linguistics, Prince Sattam bin Abdulaziz University, Al Kharj, Saudi Arabia \\ Correspondence: Yasir Hameed Alotaibi, Prince Sattam bin Abdulaziz University, Al Kharj, Saudi Arabia. E-mail: \\ y.alotaibi@psau.edu.sa
}

Received: August 23, 2019 Accepted: September 18, 2019 Online Published: October 28, 2019

doi:10.5539/ijel.v9n6p226 URL: https://doi.org/10.5539/ijel.v9n6p226

\begin{abstract}
This paper aims to discuss the analysis of verbless sentences in Modern Standard Arabic (MSA) within the Lexical Functional Grammar (LFG) framework. It discusses the previous analyses in transformational grammar and shows some problems in these analyses, arguing that LFG is more flexible and able to analyze this kind of sentences with fewer problems. This paper argues that verbless sentences in MSA should be divided into two types: the first is when the second part of a verbless sentence is an adjective, and in this type, we argue that the adjective should be analyzed as a predicate within the single-tier analysis. The second type is verbless sentences that contain a nonadjectival complement, and this type is analyzed as containing a null copula within the double-tier analysis.
\end{abstract}

Keywords: single-tier, double-tier, null copula, Lexical Functional Grammar

\section{Introduction}

In Modern Standard Arabic (MSA), there are two types of sentences: verbal sentences and nominal sentences. Verbal sentences contain a lexical verb, a copula, or an auxiliary preceding a lexical verb. Copulas and verbs in MSA can be in the perfective form or imperfective form. The perfective form in MSA is usually used to indicate the past tense and the imperfective form the present. The following four examples show four types of sentences in MSA: the example in (1a) contains a nominal sentence that lacks a verb, the example in (1b) contains a sentence that has a lexical verb, the example in (1c) contains a sentence that has a copula, and example (1d) contains an auxiliary preceding a lexical verb.

(1) a. zayd-un qāimim-un.

Zayd-NOM standing-NOM

'Zayd (is) standing'

b. dahaba zayd-un iilā al-madrasat-i.

go.PFV.3SGM Zayd-NOM to DEF-school-GEN

'Zayd went to the school'

c. zayd-un kāna fī al-madrasat-i.

Zayd-NOM be.PFV.3SGM at DEF-school-GEN

'Zayd was at the school'

d. zayd-un kāna yal ${ }^{\mathrm{c} a b u} \quad$ fì al-hadīqat-i.

Zayd-NOM be.PFV.3SGM play.IPFV.3SGM in DEF-garden-GEN

'Zayd was playing in the garden'

This paper discusses verbless sentences, in which a sentence does not include any copula or verb. The syntactic problem in this kind of sentence is finding a correct predicate. As will be shown below, some analyses suggest that there is a null copula that should function as a predicate, and other analyses assume that the second part of this type of sentence should be the correct predicate. We will discuss all these opinions about verbless sentences in transformational grammar and the Lexical Functional Grammar (LFG) framework, contributing a new LFG analysis that argues for using the null copula as a predicate in some types of verbless sentences in MSA and the second part of the sentence as a predicate in others. 
The paper is organized as follows: section 2 shows the data of verbless sentences in MSA. Section 3 discusses three analyses in transformational grammar. The first analysis is the small clause analysis, in which a verbless sentence is analyzed as a small clause that does not contain a tense. The second analysis is the null copula, which analyzes verbless sentences as containing a null copula that should be the predicate of the sentence. The third analysis is the empty $T$; this approach analyzes verbless sentences as containing a tense but not having a verb. In this section, we argue against the three analyses in transformational grammar by showing some problems in the three approaches. Section 4 introduces the LFG framework and the analysis of verbless sentences through this framework. It discusses the single-tier analysis and the double-tier analysis in LFG. In the former, verbless sentences are analyzed as sentences that contain tenses but do not contain verbs or copulas; in this case, the predicate is the second part of the sentence. In the latter, verbless sentences are analyzed as containing null copulas that should function as predicates. This paper argues that both analyses should be used in analyzing verbless sentences in MSA. Section 5 compares the analyses of verbless sentences in transformational theories and LFG, suggesting that LFG is more flexible and can analyze this kind of sentence more simply and with fewer problems.

\section{Data}

Traditional grammar in Arabic divides sentences into two types depending on the first word. If the sentence begins with a noun or noun phrase, it is classified as a nominal sentence, and if it begins with a verb, it is analyzed as a verbal sentence. This means that nominal sentences may or may not contain a verb (see Ryding, 2005). The following two examples should be nominal sentences in traditional Arabic grammar:

(2) a. zayd-un qā?im-un.

Zayd-NOM standing-NOM

'Zayd (is) standing'

b. zayd-un dahaba Pila al-madrasat-i.

Zayd-NOM go.PFV.3SGM to DEF-school-GEN

'Zayd went to the school'

The two examples above begin with a noun, but example (2a) does not contain a verb, while example (2b) contains a verb that follows the noun. Traditional grammarians would analyze the second sentence as a nominal sentence because of the difference in agreement between preverbal and postverbal nouns. We will assume that the sentence in (2b) is a verbal sentence because it contains a verb, and the verbless sentences that will be discussed in this paper are sentences that do not contain a verb.

Verbless sentences are always indicative sentences that denote the present tense, which is simply understood in this type of sentence. They contain two parts: the first part is the subject, or the topic, which we begin with, and the second is the predicate, which contains new information. The subject is usually a definite noun phrase or pronoun, while the predicate can be expressed in a variety of classes of words; that is, it can be a noun, adjective, pronoun, adverb or prepositional phrase (see Ryding, 2005). The following examples illustrate these types of verbless sentences in MSA: 


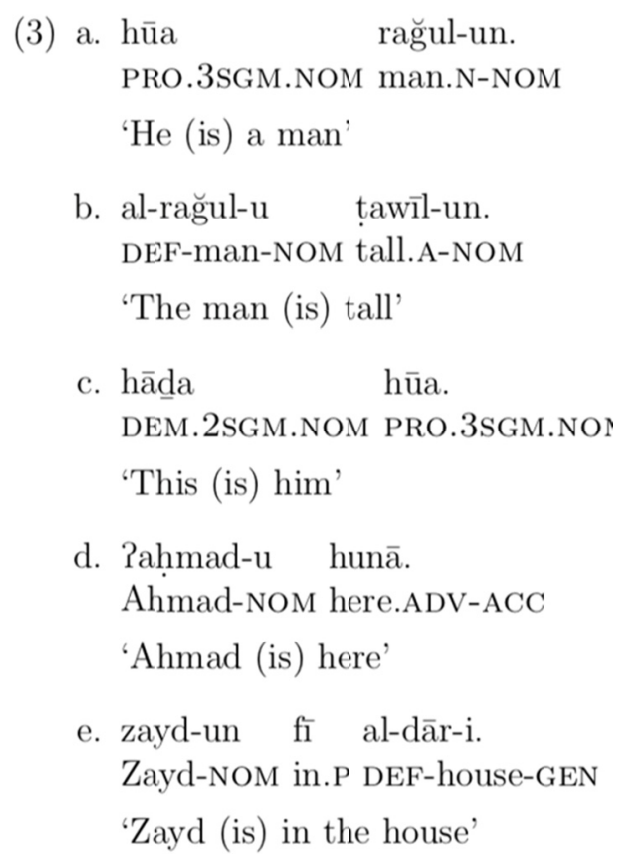

The subject in this construction can be a pronoun, as shown in (3a); a demonstrative pronoun, as shown in (3c); a noun, as shown in the rest of the examples; or other types of words. However, we are more concerned with the predicate, and the examples above show different types of predicates that can occur in this construction. We exclude the verbal predicate, which is believed in traditional grammar to be a predicate in a nominal sentence, but we assume in this paper that this is not true and that if the predicate is verbal, the sentence is a verbal sentence containing a subject that precedes the verb. Example (3a) contains a noun functioning as a predicate, example (3b) contains an adjective, example (3c) contains a pronoun, example (3d) contains an adverb, and example (3e) contains a prepositional phrase. Importantly, these predicates are different in regard to the agreement with the subject. The type of predicate that usually shows agreement with the subject is the adjective. If the predicate is an adjective, it should agree with the subject in number and gender. The following examples illustrate the adjective in example (3b), which is tawil-un, 'tall', with a feminine subject in (4a) and a plural subject in (4b):

(4) a. laylā țawīlat-un /*tawīl-un.

Layla-SGF-NOM tall.SGF-NOM /tall.SGM-NOM

'Layla (is) tall'

b. al-țullāb-u tiwāl-un /*tawīl-un.

DEF-student-PLM-NOM tall.PLM-NOM /tall.SGM-NOM

'The students (are) tall'

The subjects in the preceding examples carry a nominative case marking, while the predicates have the same case marking except in examples (3d) and (3e). In the former, the predicate is an adverb, and adverbs in MSA usually carry an accusative case marking, while the predicate in the latter contains a prepositional phrase, and in MSA, any noun that is preceded by a preposition should carry a genitive case marking.

Interestingly, all the examples that illustrate verbless sentences in (3) can occur with a verbal copula, denoting the present tense, which is yakin. In this case, the subject will keep its nominative case, but the predicate will be in the accusative case. The following examples illustrate the examples in (3) with the verbal copula yakun. 
(5) a. hūa yakūnu rağul-an.

PRO.3SGM.NOM be.IPFV.3SGM man.N-ACC

'He is a man'

b. al-rağul-u yakūnu țawīl-an.

DEF-man-NOM be.IPFV.3SGM tall.A-ACC

'The man is tall'

c. hāda yakūnu Tiyyahu.

DEM.2SGM.NOM be.IPFV.3SGM PRO.3SGM.ACC

'This is him'

d. Paḥmad-u yakūnu hunā.

Ahmad-NOM be.IPFV.3SGM here.ADV-ACC

'Ahmad is here'

e. zayd-un yakūnu fī al-dār-i.

Zayd-NOM be.IPFV.3SGM in-P DEF-house-GEN

'Zayd is in the house'

There are some differences between the verbless sentences in (3) and the copular sentences in (5). The first difference is in the case marking of the predicate, as stated above. The predicate is in nominative case in verbless sentences and in accusative case in copular sentences, as shown in the examples of the two groups. The second difference is in the semantic meaning of verbless sentences and copular sentences. When the verbal copula is used, it emphasizes the relationship between the subject and the predicate, which confirms the meaning of the sentence. The third difference is that in copular sentences, the subject can be omitted, and the sentence is still grammatical, while this omission is impossible with verbless sentences. The following examples illustrate this difference, as the example of a copular sentence in (6a) is grammatical in spite of the omission of the subject, and the example of a verbless sentence in (6b) is ungrammatical. In example (6a), the copula agrees with the omitted subject in number, gender and person, which makes the omission possible. In contrast, example (6b) contains only a prepositional phrase, which does not agree with any subject; therefore, this example is ungrammatical.

(6) a. yakūnu fī al-dār-i.

be.IPFV.3SGM in-P DEF-house-GEN

'He is in the house'

b. ${ }^{*}$ fì al-dār-i.

in-P DEF-house-GEN

'He is in the house'

In addition to the verbal copula that can occur in verbless sentences, a pronoun can be inserted between the subject and predicate in verbless sentences. This pronoun usually appears in a verbless sentence that contains a definite predicate, as shown in (7a). Importantly, a copula sometimes occurs with this pronoun, and the predicate may carry an accusative case marking, as shown in (7b), or a nominative case marking, as shown in(7c): 
(7) a. zayd-un hūwa al-qāîim-u.

Zayd-NOM PRO.3SGM.NOM DEF-standing-NOM

'Zayd is (he) the standing'

b. yakūnu zayd-un hūwa al-qāim-a.

be.IPFV.3SGM Zayd-NOM PRO.3SGM.NOM DEF-standing-ACC

'Zayd is (he) the standing'

c. yakūnu zayd-un hūwa al-qā?im-u.

be.IPFV.3SGM Zayd-NOM PRO.3SGM.NOM DEF-standing-ACC

'Zayd is (he) the standing'

We will return to this pronoun in section 4.4 .3 below and show that some researchers believe that this pronoun should be analyzed as a copula in this construction.

\section{The Analysis in Transformational Grammar}

This section discusses three analyses for verbless sentences in Arabic and other languages within transformational theories: the small clause, the null copula and the empty T approach. We will explain the main ideas in these approaches and show evidence and problems that are discussed in the literature. The small clause suggests that verbless sentences are small clauses that do not contain any tense, while the null copula and the empty $\mathrm{T}$ approach suggest that they are tensed clauses with a null copula in the former and without a null copula in the latter.

\subsection{The Small Clause Approach}

Hebrew and MSA share the structure of verbless sentences, and Mouchaweh (1986) and Rapoport (1987) use the so-called small clause analysis to analyze verbless sentences in Hebrew. They claim that verbless sentences have no functional projection and that the structure contains only the lexical projection. The subject and the predicate in verbless sentences occur in a small clause that contains no temporal projection. Therefore, verbless sentences in this approach are the same as embedded or subordinate clauses in many languages. In other words, this approach assumes that the structure of verbless sentences is the same as that of the embedded clauses David happy and Sue a good friend in the following English examples:

\section{(8) a. He found David happy.}

\section{b. She considers Sue a good friend.}

If we assume that verbless sentences contain no temporal projection, we should represent an example such as ( $3 \mathrm{~b}$ ) (repeated as (9a) below) in the simple tree shown in (9b):

(9) a. al-ră̆ul-u țawīl-un. DEF-man-NOM tall.A-NOM

'The man (is) tall'

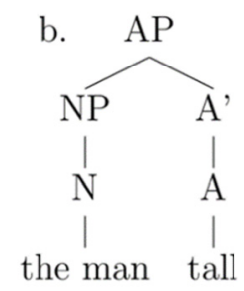

In his discussion of Arabic dialects, Benmamoun (2000) lists some problems in this analysis that are applicable toMSA. The first problem is that temporal adverbs, which should not occur in infinite clauses, can occur in verbless sentences. In this case, adverbs that indicate the present tense can occur with verbless sentences, and they are grammatical, as illustrated in (10a). In contrast, past or future adverbs cannot occur in verbless sentences, and they are ungrammatical, as shown in (10b), where there is a past adverb, and in (10c), where a future adverb occurs. The fact that adverbs referring to the present tense can occur with verbless sentences, whereas adverbs referring to the past and the future tense cannot, is evidence against the small clause analysis, supporting the 
argument that this analysis is not the correct analysis for verbless sentences in MSA.

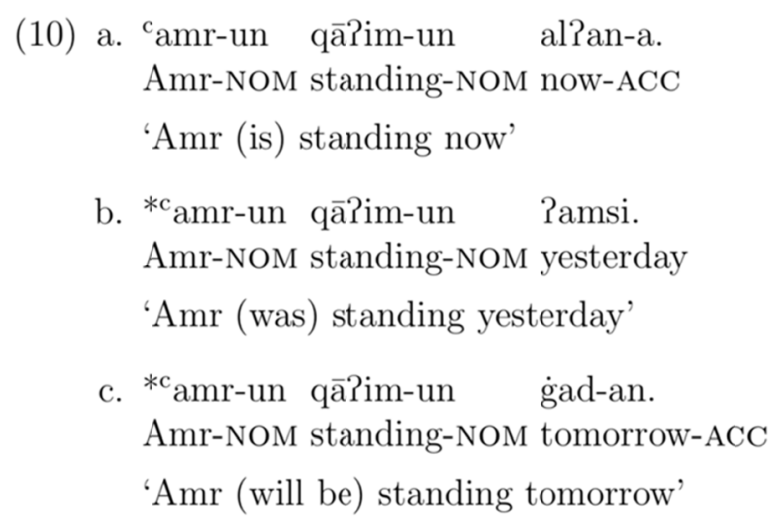

The second problem in the small clause analysis is that verbless sentences can be embedded in a matrix clause, and in this structure, verbless sentences have their own tense, which can differ from that of the matrix clause. For example, the verbless sentences in the following examples have a present tense, while the main clause has the past tense interpretation in (11a) and future tense interpretation in (11b), and both examples are grammatical, as shown below. These examples show that verbless sentences have their own tense interpretation and cannot be dependent on the tense interpretation of the main clause; therefore, they are finite clauses and cannot be analyzed as small clauses.

(11) a. qāla sālim-un camr-un qāim-un alian-a.

say.PFV.3SGM Salem-NOM Amr-NOM standing-NOM now-ACC

'Salem said that Amr (is) standing now'

b. sa-yaqūlu sālim-un camr-un qā?im-un

FUT-say.IPFV.3SGM Salem-NOM Amr-NOM standing-NOM

al?an-a.

now-ACC

'Salem will say that Amr (is) standing now'

The third problem is related to transformational grammar, in which it is assumed that the $\mathrm{T}$ head assigns nominative case to the subject. In verbless sentences, the subject has a nominative case marking, which should be assigned by $\mathrm{T}$; therefore, this clause is a finite clause containing a $\mathrm{T}$ head.

The fourth problem facing this analysis is in wh-question constructions, where the wh-word can precede the subject or the predicate in the question form, as shown below. Therefore, verbless clauses are CPs.

(12) a. man fī al-sayyārat-i?

who in DEF-car-GEN

'Who is in the car?'

b. Payna zayd-un?

where Zayd-NOM

'Where is Zayd?'

More problems with the small clause analysis are mentioned by Alotaibi (2018a), who adds that the fact that verbless sentences can occur on their own without matrix clauses, as illustrated in (3) above, supports that they are not small clauses, which should be subordinate clauses. Additionally, the coordination test shows that verbless sentences are not small clauses because they can be coordinated with full verbal sentences, as shown in (13a), and the predicate in verbless sentences can also be coordinated with a lexical verb, as shown in (13b): 
(13) a. zayd-un nā?im-un wa ${ }^{c}$ amr-un dahaba ?lā

Zayd-NOM asleep-NOM and Amr-NOM go.PFV.3SGM to

al-madrasat-i.

DEF-school-GEN

'Zayd is asleep and Amr went to the school'

b. sālim-un muğtahid-un wa yadhabu ilā al-madrasat-i.

Salem-NOM diligent-NOM and go.IPFV.3SGM to DEF-school-GEN

'Salem is diligent and goes to the school'

It is clear from the previous discussion that verbless sentences are not small clauses and that they are finite clauses containing a present tense interpretation. However, the possible analyses based on this assumption suggest that there is a null verb in this construction or assume that the tense feature comes from another type of word in this construction. The following analyses represent the two possibilities.

\subsection{The Null Copula Approach}

Bakir (1979) argues that verbless sentences contain a null verbal copula. In his analysis, he suggests that the first NP in a verbless sentence is a topic and that the subject is a pronoun that occurs after the copula. The copula and the subject are deleted in this analysis, meaning that the first word in this construction is a topic, and the second word is the complement of the missing copula. Bakir (1979) tries to reduce the gap between Arab grammarians and contemporary linguists in his analysis by adopting the main assumption in traditional grammar about verbless sentences. A similar analysis is proposed by Fassi Fehri (1993), who suggests that the structure of verbless sentences is the same as that of verbal copulas when the copula appears in the past or present tense. The only difference between the two constructions is that verbless sentences phonetically contain an empty copula.

Fassi Fehri (1993) argues that all the problems in the small clause analysis, especially the grammaticality of adverbs that have a present tense interpretation and the ungrammaticality of adverbs that have a past tense interpretation (as shown in the examples in (10), verbless sentences accept adverbs that denote the present tense), can be used to motivate an analysis of verbless sentences as containing a null copula. However, we believe that these problems with small clauses, including present tense adverbs, support the null copula analysis and the empty $\mathrm{T}$ analysis, as will be shown in the following section, because they show that this construction is finite. This does not mean that a verbless sentence contains a null copula; thus, we can argue that verbless sentences are finite but do not contain verbs.

The most important argument against the null copula analysis is that the copula in MSA assigns an accusative case marking to its predicate, meaning that if we assume that there is a covert copula in verbless sentences, then the covert copula should be the same as the overt copula in assigning an accusative case marking to the predicate (see Dechaine, 1993; Al-Horais, 2006). The following examples show that the copula yakun, which has a present tense interpretation, in example (14a) and the copula kan, which has a past tense interpretation, in (14b) assign an accusative case marking to their predicates, while the accusative case marking in the verbless sentence in (14c) makes it ungrammatical. This argument is used to support analyzing verbless sentences as sentences that contain no copula.

(14) a. ḩālid-un yakūnu muğtahid-an.

Khaled-NOM be.IPFV.3SGM diligent-ACC

'Khaled is diligent'

b. hāalid-un kāna muğtahid-an.

Khaled-NOM be.PFV.3SGM diligent-ACC

'Khaled was diligent'

c. *hāāid-un muğtahid-an.

Khaled-NOM diligent-ACC

'Khaled (is) diligent'

Another argument against analyzing verbless sentences as containing a null or deleted copula comes from Jelinek (1981) and Aoun et al. (2010), who contend that there is no interpretation for the fact that the only the covert copula is in the present tense. In contrast, the copula must appear in the past and the future tense in MSA. 
In other words, there is no special property in the present construction, leading us to assume that the copula is deleted in the present tense. The following examples are missing the copula kan in the past and sa-yakun in the future tense; therefore, they are ungrammatical:

(15) a. *2aḥmad-u muğtahid-un Pamsi. Ahmad-NOM diligent-NOM yesterday

'Ahmad (was) diligent yesterday'

b. *2ahmad-u muğtahid-un gad-an. Ahmad-NOM diligent-NOM tomorrow-ACC

'Ahmad (will be) diligent tomorrow'

\subsection{The Empty T Approach}

Jelinek (1981) and Benmamoun (2000) argue that verbless sentences contain tense but have no covert copula. They propose that there is a difference between the present and the past tense in copula and verbless constructions. In the past tense, the tense attracts the verb, which means that the sentence must contain a verb; if there is no verb, then one should be inserted. In contrast, the tense in the present tense does not attract a verb, meaning that this kind of structure does not need a verb even though it contains a tense feature. It is assumed that sentences with a past tense interpretation have the feature $[+\mathrm{V}]$ in the functional category $\mathrm{T}$, while this feature does not exist in the present tense. We can say that this analysis falls between the two previous analyses. It does not argue that verbless sentences are small clauses or contain a covert copula; therefore, this analysis differs from the previous two analyses and attempts to avoid the expected problems in transformational grammar.

Some evidence supports this analysis, as stated by Benmamoun (2000). Importantly, this analysis solves the problems listed above regarding the small clause analysis. It explains why this structure contains a present tense feature and allows the occurrence of temporal adverbs that indicate the present tense only. Additionally, it shows that verbless sentences are main clauses that cannot be embedded in another main clause and that they are CPs that allow the wh-word to precede the subject. For the problems in the null copula analysis, this approach can explain the absence of an accusative case marking on the predicate, meaning that there is no accusative case marking because there is no copula assigning this case.

Another argument in support of this analysis comes from expletives. Verbless sentences allow expletives, which means that there is a functional category that requires the expletive because it is not required by a lexical category, as stated by Aoun et al. (2010). The following example illustrates the occurrence of an expletive in a verbless sentence:

(16) hunāka rağul-un fì al-dār-i.

there man-NOM in DEF-house-GEN

'There is a man in the house'

We believe that this approach in transformational theories shows the complexity of these theories because it requires the assumption that there is an empty $\mathrm{T}$ that is different in verbless sentences only. As shown above, the copula appears in the present tense in MSA, and in this approach, it is not clear why the T should be empty in verbless sentences only. In the following sections, we will discuss the analysis of verbless sentences in LFG and show that LFG is more flexible and simpler than transformational theories in accounting for verbless sentences.

\section{The Analysis in LFG}

This section discusses the LFG framework. It opens with an overview of this framework in 4.1, showing the design of LFG and introducing the constituent structure (c-structure) and the functional structure (f-structure). Section 4.2 provides an analysis of copular constructions within LFG, which should be used as a basis for analyzing verbless sentences because we believe that the analysis of verbless sentences should be related to the analysis of copular constructions. This subsection shows two analyses in LFG, namely, the single-tier analysis, in which the complement in a copular construction is analyzed as the predicate, and the double-tier analysis, in which the copula is analyzed as the predicate. Section 4.3 deals with verbless sentences and provides the contribution of this paper: our argument that both the single-tier and the double-tier analysis that are used in analyzing copular constructions should be used in analyzing verbless sentences. 


\subsection{An Overview of $L F G$}

LFG is a syntactic theory that was developed in the 1970s by Joan Bresnan and Ronald Kaplan. This theory is called lexical because much syntactic work is performed in the lexicon and functional because the syntactic functions in this theory are central and are represented in a separate structure called the f-structure. Thus, LFG uses two aspects of presentation: the c-structure and the f-structure. It is similar to other syntactic theories in assuming that words should be organized into constituents, which should be licensed by rules and represented in a tree. It follows the $\mathrm{x}$-bar principle, which assumes that each phrase has a head that may occur with a specifier and a complement. Similar to other theories, LFG contains lexical categories, such as N, P, V, A and Adv, and functional categories, such as I and C. I is the head of an IP, which is a finite clause and should be filled by an auxiliary in the English language or by other inflectional words, such as verbs, in Russian (see Falk, 2001; Dalrymple, 2001). C is the head of a CP, which should be filled by a complementizer in the English language (see Bresnan, 2001; Dalrymple, 2001).

The syntactic information is shown in the f-structure in LFG, which represents a function from attributes to their values. Attributes in the f-structure can be a governable grammatical function (subject, object, etc.), a modifier (adjective), or morphosyntactic features (number, person, tense). Importantly, any f-structure must meet the well-formedness conditions of coherence, completeness and consistency. An $\mathrm{f}$-structure is coherent if and only if all the governable grammatical functions are required by a predicate, is complete if and only if it includes all the governable grammatical functions that are required by its predicate, and is consistent if an attribute has only one value (see Kaplan \& Bresnan, 1982; Bresnan, 2001; Dalrymple, 2001). The following three f-structures are not coherent, complete or consistent, respectively. In (17b), the f-structure is not coherent because the predicate requires a subject and an object, but there are two objects. In (18b), the f-structure is not complete because the predicate requires a subject and an object, but the object is unavailable. Finally, the f-structure in $(19 \mathrm{~b})$ is not consistent because the attribute NUM has two values.

(17) a. *John met David Louise.

b. $\left[\begin{array}{ll}\text { PRED } & \text { 'MEET }<(\text { SUBJ }),(\text { OBJ })>' \\ \text { TENSE } & \text { past } \\ \text { SUBJ } & {\left[\begin{array}{ll}\text { PRED } & \text { 'JOHN'} \\ \text { NUM } & \text { SG } \\ \text { PERS } & 3\end{array}\right]} \\ \text { OBJ } & {\left[\begin{array}{ll}\text { PRED } & \text { 'DAVID' } \\ \text { NUM } & \text { SG } \\ \text { PERS } & 3\end{array}\right]} \\ \text { OBJ } & {\left[\begin{array}{ll}\text { PRED } & \text { 'LOUISE' } \\ \text { NUM } & \text { SG } \\ \text { PERS } & 3\end{array}\right]}\end{array}\right]$

(18) a. *John met.

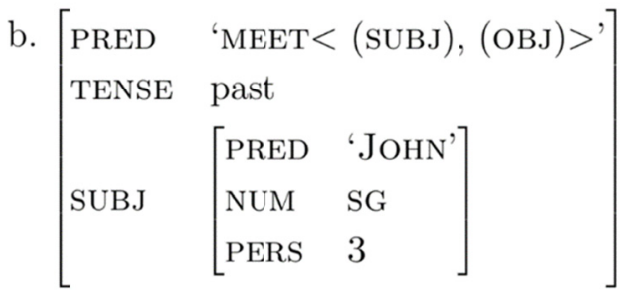


(19) a. The boy cry.

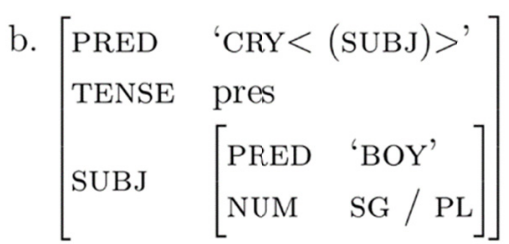

At the end of this overview, we provide a c-structure and an f-structure for a grammatical sentence to show how LFG works. The following c-structure and f-structure represent the analysis of a simple sentence such as John is meeting Louise. Importantly, there are two analyses for the auxiliary in this sentence, and they are similar to the two analyses of copular constructions in LFG, as will be shown later. In the f-structure in (20b), the sentence is analyzed as containing a predicate that is the lexical verbmeet; this predicate requires a subject and an object, and both are available. In contrast, the f-structure in $(20 \mathrm{c})$ shows that the predicate is the auxiliary and requires a nonthematic subject and an XCOMP. The lexical verb is the predicate of the XCOMP, and the subject in the embedded f-structure is controlled by the subject in the main predicate (see Falk, 1984; Alotaibi, 2017a).

(20) a.

IP

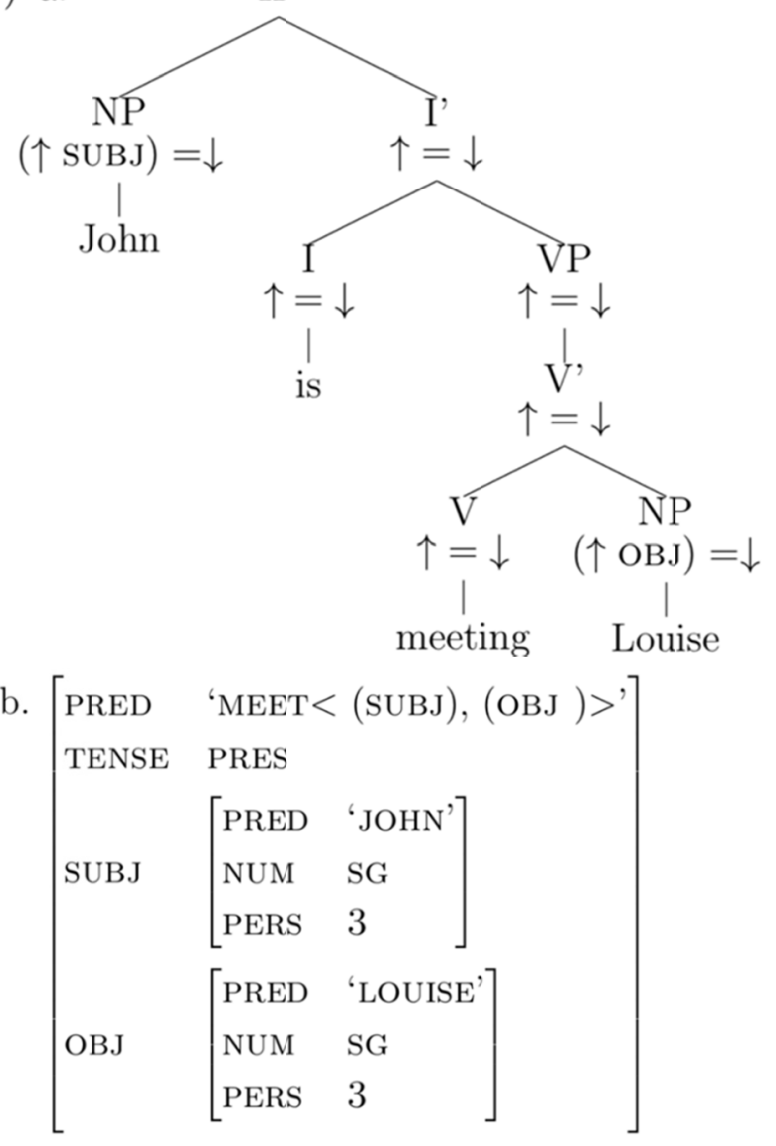


c. $\left[\begin{array}{ll}\text { PRED } & \text { 'BE }<(\text { XCOMP })>(\text { SUBJ }) ' \\ \text { TENSE } & \text { PRES } \\ \text { SUBJ } & 1\left[\begin{array}{ll}\text { PRED } & \text { 'JOHN' } \\ \text { NUM } & \text { SG } \\ \text { PERS } & 3\end{array}\right] \\ \text { XCOMP } & {\left[\begin{array}{ll}\text { PRED } & \text { 'MEET }<(\text { SUBJ }),(\text { OBJ })>' \\ \text { SUBJ } & 1\end{array}\right]} \\ \text { OBJ } & {\left[\begin{array}{ll}\text { PRED } & \text { 'LOUISE' } \\ \text { NUM } & \text { SG } \\ \text { PERS } & 3\end{array}\right]}\end{array}\right]$

\subsection{Copular Constructions in $L F G$}

The analysis of verbless sentences in LFG should be linked to the analysis of copular constructions in this framework. Thus, before we start the discussion of verbless sentences, we should discuss the analysis of copular constructions in the LFG theory. The analysis of the copula in LFG has been discussed by Rose'n (1996), Butt et al. (1999), Dalrymple et al. (2004), Nordlinger and Sadler (2007) and Attia (2008), who consider two quite different analyses in LFG for copular constructions, namely, the single-tier and the double-tier analysis. The two analyses will be discussed in the following sections.

\subsubsection{The Single-Tier Analysis}

In the single-tier analysis, the nonverbal predicate is analyzed as a predicate, selecting for a subject. In this case, the copula is represented in the f-structure by a feature that shows the tense of the clause. The f-structure in (21b) shows the analysis of the copular sentence in (21a):

(21) a. John was a teacher.

b. $\left[\begin{array}{ll}\text { PRED } & \text { 'TEACHER }<(\text { SUBJ })> \\ \text { TENSE } & \text { past } \\ \text { SUBJ } & {\left[\begin{array}{ll}\text { PRED } & \text { 'JOHN'} \\ \text { NUM } & \text { SG } \\ \text { PERS } & 3\end{array}\right]}\end{array}\right]$

The value of the attribute PRED in the f-structure contains the list of arguments that are required by the predicate of the sentence, which is teacher in this analysis. The copula is analyzed as a feature denoting the tense of the clause, which is the past tense. The value of SUBJ is an embedded f-structure showing the information of the subject of this clause.

\subsubsection{The Double-Tier Analysis}

The second possible analysis for copular constructions analyzes the copula as the head of this structure. In this case, the copula is assumed to require a subject and complement. However, in this analysis, there are two possibilities for the analysis of the complement: we can assume that the copula requires a grammatical function that is filled by a single word or by a predicate that shares the same subject with the copula, and in this case, the structure will be analyzed as biclausal. The first complement is called closed complement and the second open complement (see Dalrymple et al., 2004).

The following f-structure illustrates the first possibility, in which the complement is closed: 
(22) a. John was a teacher.

b. $\left[\begin{array}{ll}\text { PRED } & \text { 'BE }<(\text { SUBJ }),(\text { GF })>\text { ' } \\ \text { TENSE } & \text { past } \\ \text { SUBJ } & {\left[\begin{array}{ll}\text { PRED } & \text { 'JOHN' } \\ \text { NUM } & \text { SG } \\ \text { PERS } & 3\end{array}\right]} \\ \text { GF } & {\left[\begin{array}{ll}\text { PRED } & \text { 'TEACHER' } \\ \text { NUM } & \text { SG } \\ \text { PERS } & 3\end{array}\right]}\end{array}\right.$

The value of the attribute PRED in this f-structure is the copula, and it requires two functions: the first is the subject, and the second is a grammatical function (GF) that is filled by the noun teacher, which is shown by the embedded f-structure that is the value of the attribute GF.

If we assume that the complement is open, we should analyze it as a predicate that shares the same subject with the main predicate. In this case, the relationship between the main and the embedded clause is functional control, and we should assume that the copula is a raising verb (Note) that does not impose a semantic constraint on the raised subject. The following f-structure shows the analysis of the previous sentence within this approach:

(23) a. John was a teacher.

b. $\left[\begin{array}{ll}\text { PRED } & \text { 'BE }<(\text { XCOMP })>(\text { SUBJ }) ' \\ \text { TENSE } & \text { past } \\ \text { SUBJ } & 1\left[\begin{array}{ll}\text { PRED } & \text { 'JOHN' } \\ \text { NUM } & \text { SG } \\ \text { PERS } & 3\end{array}\right] \\ \text { XCOMP } & {\left[\begin{array}{ll}\text { PRED } & \text { 'TEACHER }<(\text { SUBJ })> \\ \text { SUBJ } & 1\end{array}\right]}\end{array}\right]$

In this f-structure, the list of arguments required by the copula are the open grammatical function XCOMP and the raised argument SUBJ. The SUBJ appears outside the angled brackets because it is not a semantic argument of the copula, while the XCOMP appears inside the angled brackets. The subject of the copula, John, controls the subject of the subordinate clause, as is shown in the f-structure by the number 1 in a square, which connects the two subjects.

\subsection{Verbless in LFG}

In this paper, we assume that both the single-tier and double-tier analyses should be adopted for analyzing verbless sentences in MSA. We suggest that verbless sentences in MSA should be divided into two groups: the first group contains complements that should function as predicates, and the single-tier analysis should be adopted in this case. The second group contains complements that are not valid predicates, and in this case, the double-tier analysis should be chosen. We argue that when the nonverbal complement is an adjective, it should be analyzed as a predicate that requires a subject. In contrast, when the nonverbal complement in the verbless sentence is a noun, pronoun, adverb or prepositional phrase, it should not be analyzed as a predicate, and the structure should be analyzed as containing a null copula that subcategorizes for a subject and a complement. Section 4.3.1 discusses the single-tier analysis in verbless sentences, and section 4.3.2 discusses the double-tier analysis. In addition, section 4.3.3 discusses a special structure in MSA when a pronoun separates the two words in a verbless sentence.

\subsubsection{The Single-Tier Analysis in Verbless Sentences}

This section discusses the first type of verbless sentence in MSA. In this type, the nonverbal predicate is an adjective, and we argue that this type should be analyzed with the single-tier analysis. As mentioned above, the nonverbal complement of a verbless sentence in MSA can be an adjective. The following examples illustrate this 
type of verbless sentence:

(24) a. zayd-un țawīl-un.

Zayd-NOM tall.A-NOM

'Zayd (is) tall'

b. zaynab-u ğamilat-un.

Zaynab-NOM beautiful.A-NOM

'Zaynab (is) beautiful'

In their analysis of the complement of copular constructions in the English language, Dalrymple et al. (2004) argue that the main properties of a predicate that subcategorizes for a subject are that it occurs as the syntactic head of a predicate phrase that contains a prototypical subject and shows agreement with the subject if verbs in the language agree with their subjects. Based on these criteria, Dalrymple et al. (2004) argue that when the nonverbal complement in the copular construction in the Japanese language is an adjective, it should be analyzed as an open complement because adjectives in this language can be the syntactic head and agree with their subjects. In contrast, they argue that adjectival complements in copular constructions in the English language should not be analyzed as open complements because they cannot be syntactic heads and do not agree with subjects.

In MSA, adjectives in verbless sentences head their predicate phrases and agree with subjects in gender and number, as shown in the following examples:

$$
\begin{aligned}
& \text { a. zayd-un țawīl-un. } \\
& \text { Zayd.SGM-NOM tall.SGM.A-NOM } \\
& \text { 'Zayd (is) tall' } \\
& \text { b. fațimat-u țawilat-un. } \\
& \text { Fatemah-SGF-NOM tall.SGF.A-NOM } \\
& \text { 'Fatemah (is) tall' } \\
& \text { c. al-țullab-u țawilūna. } \\
& \text { DEF-student.PLM-NOM tall.PLM.A-NOM }
\end{aligned}
$$

'The students (are) tall'

In example (25a), the proper noun Zayd is masculine and singular, and the adjective tawil-un, 'tall', is the same. In example (25b), both the subject and the adjective are feminine and singular. In (25c), both the subject and the adjective are masculine and plural. The agreement between the subject and the adjective supports analyzing the adjective as a predicate in verbless sentences in MSA because verbs in MSA always agree with their subjects in number and gender.

Another argument in support of analyzing adjectives as predicates comes from the similarities in semantic meaning between adjectives and verbs. Adjectives in MSA are always derived from verbs and therefore refer to the event or action denoted by a verb. Additionally, adjectives in MSA can subcategorize for objects when they are derived from transitive verbs. This is strong evidence in support of analyzing adjectives as predicates. The following examples show adjectives in MSA with objects in accusative case following them:
a. $\breve{g} \bar{a} \mathrm{Ta}$
al-ḍārib-u
zayd-an.
come.PFV.3SGM DEF-hitter.APTCP-NOM Zayd-ACC
'The hitter of Zayd came'

b. hāda al-dāris-u nahww-an.

This.NOM DEF-studying.APTCP-NOM syntax-ACC

'This is the man who studied syntax'

The two examples above show that active participles, which function in MSA as adjectives, can subcategorize for objects carrying an accusative case marking. In the first example, the active participle al-darib-u, 'the hitter', requires an object, which is Zayd, which carries an accusative case marking. The second example is the same in that the active participle requires an object function, which is filled by the noun syntax. The similarities between 
adjectives and verbs in MSA suggest that adjectives should be analyzed as predicates in verbless sentences.

In addition, the single-tier analysis is more economical in that it assumes less structure, meaning that when we analyze verbless sentences that contain adjectival complements within the single-tier analysis, we assume that the structure contains one clause, which is headed by the adjective. Moreover, in this analysis, we avoid null copulas, which are required in the double-tier analysis for verbless sentences, as LFG usually avoids null items if they are not necessary.

Additionally, other languages may support our assumption about adjectives. In Abkhaz and Turkish, adjectives can carry verbal morphology, specifying the tense of the clause and showing agreement with the subjects (see Curnow, 2000; Nordlinger \& Sadler, 2007). Additionally, we can claim that adjectives in MSA may denote some aspects and are similar to verbs in this regard. This is not a new claim for Arabic because some researchers claim that Arabic dialects, such as Egyptian and Syrian, use the active participle form to indicate some aspects (see Eisele, 1990; Boneh, 2010). Moreover, Boneh (2010) argues that active participles in the Syrian dialect function as verbs by indicating tense and aspect. This means that adjectives are close to verbs in their morphological form and syntactic function in the Arabic language and other languages.

Thus, this paper argues that when nonverbal predicates are adjectives in verbless sentences in MSA, they should be analyzed as predicates. The following f-structure shows the analysis of the verbless sentence in (25a), repeated as (27a) below. The f-structure in (27b) shows that the adjective tall is the predicate of the sentence and requires a subject function, which is filled by the subject Zayd.

$(27)$

$$
\begin{aligned}
& \text { a. zayd-un tawìl-un. } \\
& \text { Zayd.SGM-NOM tall.SGM.A-NOM } \\
& \text { 'Zayd (is) tall' } \\
& \text { b. }\left[\begin{array}{ll}
\text { PRED } & \text { 'TALL < (SUBJ)>' } \\
\text { TENSE } & \text { PRES } \\
\text { SUBJ } & {\left[\begin{array}{ll}
\text { PRED } & \text { 'ZAYD' } \\
\text { NUM } & \text { SG } \\
\text { PERS } & 3
\end{array}\right]}
\end{array}\right]
\end{aligned}
$$

This f-structure is more economical because it assumes that the verbless sentence contains a single clause that is headed by the adjective tall. The list of arguments required by the predicate contains one function, SUBJ. This requirement is fulfilled by the embedded f-structure, which is the value of the attribute SUBJ. The tense of this verbless sentence is shown by the attribute TENSE and its value PRES, which means that the tense of this sentence is present. In LFG, we do not have to find a lexical or functional category for tense, which means that we can simply add an equation such as ' $(\uparrow$ TENSE $)=$ PRES' under the lexical entry of the adjective tall, as shown in (28), to ensure that the f-structure of this sentence contains the tense feature.

$$
\begin{aligned}
& \text { (28) tawīl } A \quad(\uparrow \text { PRED })=' \text { tall }<\text { (SUBJ) }>\text { ' } \\
& (\uparrow \text { TENSE })=\text { PRES }
\end{aligned}
$$

We can also use the phrase structure rules to add the tense information, which can be done by using the empty rule, which will be discussed in the following section through the double-tier analysis; however, because we focus on the f-structure in this paper, we have added this information in the lexical entry. Finally, we note that the single-tier analysis is not only the possible analysis for this structure; we can analyze verbless sentences that contain adjectives by using the double-tier analysis if we assume that adjectives are not predicates and that this is a possible analysis for adjectives (see Alotaibi, 2019) for more information about analyzing adjectives).

\subsubsection{The Double-Tier Analysis in Verbless Sentences}

In this section, we deal with verbless sentences that contain a noun, pronoun, adverb or prepositional phrase in the second part. We assume that this kind of word or phrase cannot function as a predicate. The main reason for this assumption is that the relationship between this type of word and the subject is weak, and we should not suggest that they subcategorize for subjects in their constructions. The most important evidence is the agreement between this type of word and the subject. The following repeated examples illustrate this group of verbless sentences in MSA: 
(29) a. hūa rağul-un.

PRO.3SGM.NOM man.N-NOM

'He (is) a man'

b. hāda hūa.

DEM.2SGM.NOM PRO.3SGM.NOM

'This (is) him'

c. Pahmmad-u hunā.

Ahmad-NOM here.ADV-ACC

'Ahmad (is) here'

d. zayd-un fī al-dār-i.

Zayd-NOM in-P DEF-house-GEN

'Zayd (is) in the house'

The correct analysis for this type of complement in verbless sentences is the double-tier analysis. Thus, we assume that there is a null copula in this structure and that the null copula subcategorizes for two functions: the subject and the function filled by the second part of this structure. The following f-structure shows the analysis of the example in (29a), repeated as (30a) below:

(30) a. hūa rağul-un.

PRO.3SGM.NOM man.N-NOM

'He (is) a man'

b. $\left[\begin{array}{ll}\text { PRED } & \text { 'NULL.BE }<(\text { SUBJ }),(\text { PREDLINK })>' \\ \text { TENSE } & \text { PRES } \\ \text { SUBJ } & {\left[\begin{array}{ll}\text { PRED } & \text { 'PRO' } \\ \text { CASE } & \text { NOM }\end{array}\right]} \\ \text { PREDLINK } & {\left[\begin{array}{ll}\text { PRED } & \text { 'MAN' } \\ \text { CASE } & \text { NOM }\end{array}\right]}\end{array}\right]$

In this analysis, we assume that the null copula requires two functions: the subject and the closed complement PREDLINK, and it is closed because we assume that the noun cannot subcategorize for a subject. The noun that we mean in this analysis is the one that is not derived from a verb, meaning that all derivative words, such as talib, 'student', or mudarris, 'teacher', in MSA will be analyzed as adjectives that subcategorize for syntactic functions. As mentioned in the previous section, the deverbal words are similar to verbs and should be analyzed as predicates.

The question that should be asked here is how can we allow null words in LFG? The answer is that we can follow Dalrymple (2001) in her proposal for the empty rule in Warlpiri, which was discussed by Simpson (1991). In her analysis of Warlpiri, Simpson (1991) states that the auxiliary in this language does not appear in the perfect aspect, meaning that there are two possibilities for auxiliaries in this language. The following rule is suggested by Dalrymple (2001, p. 175) to cover both possibilities: when the auxiliary disappears in perfect aspect and appears in other aspects:

$(31) \mathrm{I}^{\prime} \longrightarrow \quad\left\{\begin{array}{c}\mathrm{I} \\ \uparrow=\downarrow\end{array}\right.$

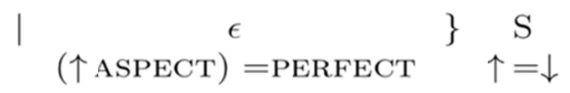

The symbol $\varepsilon$ represents the absent auxiliary in the perfect aspect, showing that this category is empty. The rule in this case allows two possibilities in Warlpiri: the first is when the auxiliary appears under I, and the second is when it disappears; in the latter case, the aspect will be perfect, as shown by the annotation $(\uparrow$ ASPECT) $=$ PERFECT, which means that the aspect of the empty category is perfect. The empty category is used by some researchers in analyzing different aspects in the Arabic language (see Attia, 2008; Alotaibi, 2014; Alotaibi, 2017b; Alotaibi, 2018b).

We can use the empty rule node for analyzing the structure of the copula in MSA, and in this case, the rule should represent the two cases of the copula: when it appears and when it disappears in verbless sentences. The following rule should cover the two possibilities of copular construction in MSA: 
(32)

$$
\left\{\begin{array}{c}
\mathrm{I} \\
\uparrow=\downarrow
\end{array}\right.
$$

$$
\left.\mid \begin{array}{cc}
\epsilon & \mathrm{S} \\
(\uparrow \text { TENSE })=\text { PRESENT }
\end{array}\right\} \begin{aligned}
& \uparrow=\downarrow \\
& \text { PR }
\end{aligned}
$$

This rule licenses the following examples in MSA, with the copula appearing in example (33a) and disappearing in example (33b). This analysis assumes that the copula is deleted in the verbless sentence in (33b). The following c-structures and f-structures provide the analysis of both sentences within LFG.
a. zayd-un yakūnu
fì al-dār-i.

Zayd-NOM be.IPFV.3SGM in-P DEF-house-GEN

'Zayd is in the house'

b. zayd-un fī al-dār-i.

Zayd-NOM in-P DEF-house-GEN

'Zayd (is) in the house'

(34) a.

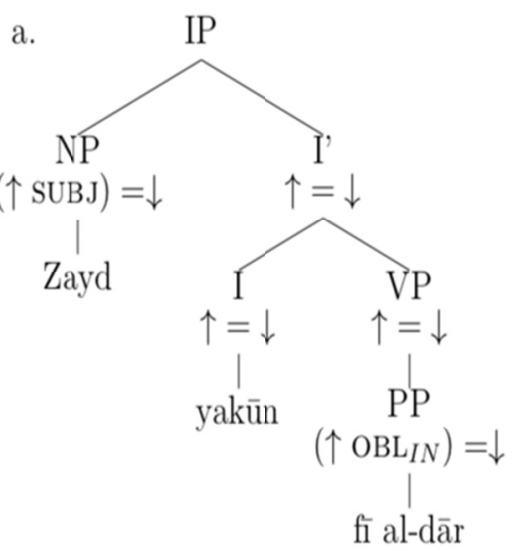

b. $\left[\begin{array}{ll}\text { PRED } & \text { 'BE }<(\text { SUBJ }),\left(\mathrm{OBL}_{I N}\right)>> \\ \text { TENSE } & \text { PRES } \\ \text { SUBJ } & {\left[\begin{array}{ll}\text { PRED } & \text { 'ZAYD' } \\ \text { NUM } & \text { SG } \\ \text { PERS } & 3\end{array}\right]} \\ \text { OBL }_{I N} & {\left[\begin{array}{ll}\text { OBJ } & \begin{array}{ll}\text { PRED } & \text { HOUSE'} \\ \text { NUM } & \text { SG } \\ \text { PERS } & 3\end{array}\end{array} \mid\right.}\end{array}\right.$

The c-structure and f-structure in (34) represent the analysis of the copular construction in (33a). In this case, the copula appears under the I node, functioning as a predicate in this sentence. It requires two functions, as shown in the f-structure. The first function is the subject, and the second is the oblique. Both functions are shown in the embedded f-structures. 


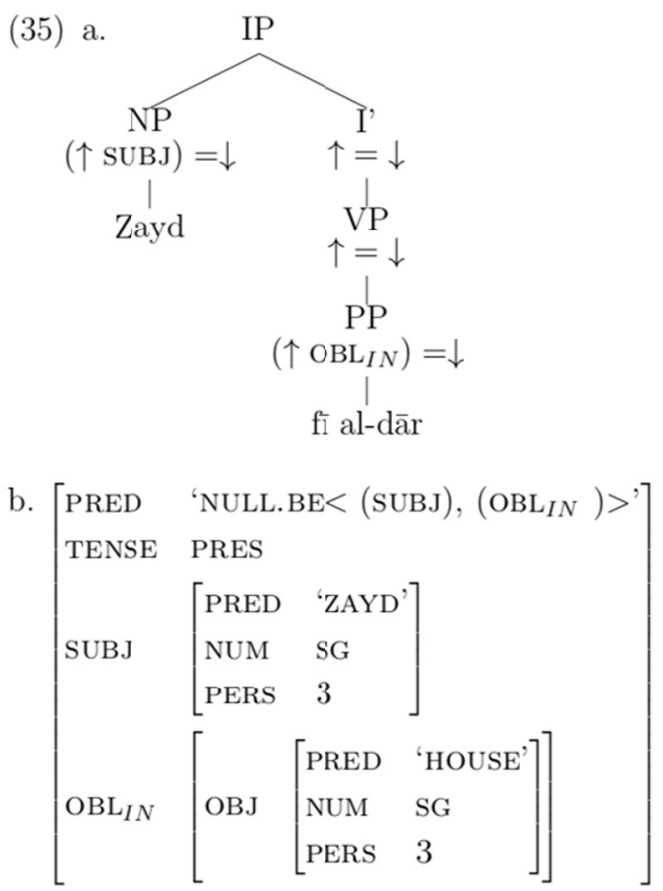

The c-structure and f-structure in (35) show the analysis of example (33b), which contains a verbless sentence that has no predicate. In this case, the missing copula does not appear in the c-structure but appears in the f-structure as a predicate that requires two functions that are required by the apparent copula in the previous example. The null copula subcategorizes for a SUBJ and OBLIN, and both requirements are satisfied by the two embedded f-structures, as shown in (35b).

\subsubsection{The Analysis of the Pronoun}

This section discusses a different structure of verbless sentences in MSA, in which a verbless sentence contains a pronoun that occurs between the subject and the predicate. This structure was explained in (7a) above and is repeated in (36) below:

$$
\begin{aligned}
& \text { (36) zayd-un hūwa al-qāimim-u. } \\
& \text { Zayd-NOM PRO.3sGm.NOM DEF-standing-NOM } \\
& \text { 'Zayd (he) (is) the standing' }
\end{aligned}
$$

Li and Thompson (1977) and Eid (1991) argue that this pronoun is a copula morpheme in Arabic and Hebrew and have called it a copula pronoun because this pronoun is similar to a copula in linking a subject with its predicate. Eid (1991) discusses some evidence from the Egyptian dialect as follows: first, this pronoun is in complementary distribution with copulas in Egyptian. Second, the pronoun shows the same agreement of verbs in the present form. Third, the position of this pronoun cannot be analyzed as a subject position.

The first evidence item means that the pronoun occurs in the present tense, in which there is no copula, and copulas occur in the past and future tenses. We believe that this is not strong evidence, as this is not true in MSA and some Arabic dialects. As stated above, the present form of the copula in MSA is yakin, and it appears optionally in MSA and some other Arabic dialects. Moreover, the present copula yakin can appear with the pronoun in MSA, as shown below:
a. zayd-un yakūnu
hūwa
al-qā?im-a.
'Zayd is (he) the standing'
b. zayd-un yakūnu hūwa al-qāim-u.
Zayd-NOM be.IPFV.3SGM PRO.3SGM.NOM DEF-standing-NOM
'Zayd is (he) the standing' 
Both examples above show that the pronoun occurs with the present form of the copula in MSA, which means that it is impossible to analyze it as a copula because two copulas do not occur together in MSA. The second evidence item discussed by Eid (1991) does not prove that this pronoun is similar to the copula because pronouns usually agree with their antecedents, which does not mean that they are verbs or similar to verbs. The third argument is the strongest evidence in Eid (1991) and raises an important question: what is the syntactic function of this pronoun? If this pronoun is not a subject, what should it be? In addition, the two examples in (37) make the issue worse because in example (37a), the complement is in accusative case, while it is in nominative case in $(37 \mathrm{~b})$, and both examples are grammatical.

Traditional grammarians argue that the pronoun is usually used between definite nouns in verbless sentences to show that the second word is a predicate and not an adjective (see Hassaan, 2008). Therefore, in example (38a), there are two possible functions for the word al- gamilat-u, 'the beautiful': it can function as an adjective modifying the preceding noun because adjectives in MSA follow their nouns, and in this meaning the clause is not complete, or it can function as a predicate if the speaker is giving information about Layla, which is that she is beautiful. In contrast, if we use the pronoun between the two words, as shown in (38b), the sentence has the second meaning, with the speaker informing the hearer that Layla is beautiful.

(38) a. laylā al-ğamīlat-u.

Layla-NOM DEF-beautiful-NOM

'Layla (is) the beautiful'

b. laylā hīa al-ğamīlat-u.

Layla-NOM pro.3SGF DEF-beautiful-NOM

'Layla (she) (is) the beautiful'

This paper suggests two analyses for the pronoun in a sentence such as (38b) above. It can be assumed to function as an adjunct if we assume that it emphasizes the subject of the sentence only. This analysis should be suggested if the predicate carries an accusative case marking with the copula, as shown in (39a), because we assume that there is only one clause in this sentence with one subject and one predicate. In contrast, the second analysis should be used if the predicate carries a nominative case marking with the copula, as shown in (39b). In this structure, we assume that a verbless sentence is embedded in a main verbless sentence. In this analysis, we analyze the pronoun as the subject of the embedded verbless sentence.

(39) a. laylā takūnu hīa al-ğamīlat-a.

Layla-NOM be.IPFV.3SGF pro.3SGF DEF-beautiful-NOM

'Layla (is) (she) the beautiful'

b. laylā takūnu hīa al-ğamīlat-u.

Layla-NOM be.IPFV.3SGF pro.3SGF DEF-beautiful-NOM

'Layla (is) (she) the beautiful'

Importantly, in the first structure, in which the pronoun is analyzed as an adjunct, there is no problem in the analysis of the verbless sentence, meaning that we should use the single-tier analysis or the double-tier analysis depending on the second part of the sentence. In (38b), the adjective can function as a predicate and subcategorizes for a subject, which is fulfilled by the proper noun Layla. The f-structure in (40) shows this analysis, in which the pronoun is represented in a set that is the attribute of the value ADJ, meaning that it functions as an adjunct.

(40) a. the single-tier analysis

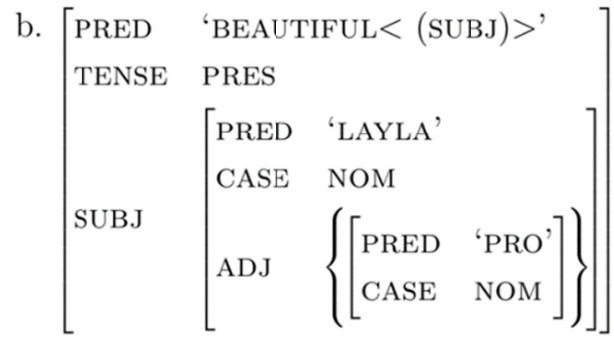


The second analysis that is suggested for the second structure has a problem in finding the predicate of the main sentence. Thus, we must assume that there is a null copula that requires a subject and a complement. The complement in this assumption is a verbless sentence that is analyzed by using the single-tier analysis because the second part of this embedded sentence is an adjective, and the pronoun will therefore be analyzed as the subject of the embedded verbless sentence. The following f-structure shows this analysis:

(41) a. the double-tier analysis

b. $\left[\begin{array}{ll}\text { PRED } & \text { 'NULL.BE }<(\text { SUBJ }),(\text { COMP })>' \\ \text { TENSE } & \text { PRES } \\ \text { SUBJ } & {\left[\begin{array}{ll}\text { PRED } & \text { 'LAYLA' } \\ \text { CASE } & \text { NOM }\end{array}\right]} \\ \text { COMP } & {\left[\begin{array}{ll}\text { PRED } & \text { 'BEAUTIFUL }<(\text { SUBJ })>' \\ \text { SUBJ } & {\left[\begin{array}{ll}\text { PRED } & \text { 'PRO' } \\ \text { CASE } & \text { NOM }\end{array}\right]}\end{array}\right]}\end{array}\right.$

\section{LFG vs. Transformational Theories}

This section compares the analysis of verbless sentences in MSA in the LFG framework and transformational theories. It opens with a comparison of the single-tier analysis in LFG with the empty $\mathrm{T}$ analysis in transformational grammar because of the similarity between them, showing why we should prefer LFG. Then, it compares the double-tier analysis with the small clause analysis and the null copula analysis in transformational grammar because all these analyses assume that verbless sentences are biclausal.

As shown above, there are two possible analyses in LFG for copular constructions in general; therefore, the two analyses, or one of them, should be used in analyzing verbless sentences. We have shown the flexibility of LFG by the single-tier and double-tier analysis and suggested that both analyses should be used in the analysis of verbless sentences in MSA. LFG avoids the small clause analysis, the problems of which are discussed above. In both the single-tier and the double-tier analysis, verbless sentences are analyzed as main clauses that indicate the present tense.

\subsection{The Single-Tier vs. the Empty T Analysis}

As stated above, the empty $\mathrm{T}$ approach assumes that the structure of verbless sentences contains tense without a null copula. This approach in transformational grammar solves some theoretical problems in the small clause analysis, such as the fact that the tense is understood in verbless sentences without a verb and the fact that verbless sentences are main clauses. Additionally, it explains the difference between copular constructions and verbless sentences in that the complement carries an accusative case marking in copular constructions and a nominative case marking in verbless sentences. However, we argue that this analysis avoids some problems by creating others. In particular, it is not plausible to create a category and assume that it is different from others in regular sentences without sufficient evidence. Additionally, we believe that this analysis solves some problems in other approaches in an overly complicated way. In addition, if we assume that present tense is special in verbless sentences, and tense does not attract a verb, we should identify some differences between the present and past tense, and this difference should not be in copular constructions only. The appearance of the present copula yakun in MSA causes some problems for this approach, and we should ask why tense attracts a verb in the present when the copula appears and does not do so in verbless sentences.

The single-tier analysis in LFG is similar to the empty T analysis with some differences. In particular, it can explain why the tense of verbless sentences is present, and there is no need in LFG to care about the case marking of the predicate because LFG does not assume that a verb must assign a case marking to its arguments, as will be shown later. Moreover, the flexibility of LFG allows it to solve these problems simply. In LFG, we do not need to assume that there is an empty $\mathrm{T}$ that is different from other Ts in that it does not attract any verb. We simply represent the tense of the clause in the f-structure as a feature, as shown in (27), repeated below as (42). What we need in this analysis is to ensure that the tense information is introduced in the f-structure by using the lexical entry of some words or the phrase structure rules, as shown above. 
(42)
a. zayd-un țawīl-un.
Zayd.SGM-NOM tall.SGM.A-NOM
'Zayd (is) tall'
b. $\left[\begin{array}{lll}\text { PRED } & \text { 'TALL }<(\text { SUBJ })> \\ \text { TENSE } & \text { PRES } \\ \text { SUBJ } & {\left[\begin{array}{ll}\text { PRED } & \text { 'ZAYD' } \\ \text { NUM } & \text { SG } \\ \text { PERS } & 3\end{array}\right]}\end{array}\right]$

Additionally, this analysis should have a simple c-structure that represents a verbless sentence without assuming any empty category. The following c-structure shows the previous verbless sentence in (42a), in which the AP, which is assumed to be the predicate of this clause, appears under the VP, which appears under I'. This means that the single-tier analysis in LFG is more economical and simpler than similar analyses in other theories.

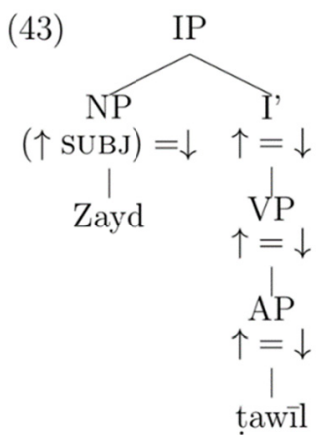

\subsection{The Double-Tier Analysis vs. Similar Approaches}

The second possible analysis for verbless sentences in LFG is the double-tier analysis, which analyzes a verbless sentence as a sentence headed by a null copula. In transformational grammar, the closest approach to the double-tier analysis is the null copula approach, which assumes that verbless sentences include a null copula. The main problem in this approach is that it does not explain that the covert copula in a verbless sentence does not assign an accusative case marking to its complement, as overt copulas do.

In the government and binding (GB) theory, the verb or the preposition must assign case to the DPs that are their sisters, meaning that the head should assign the case of the complement and the specifier. The idea of assigning the case marking has been changed in the minimalist approach to checking the case marking because of the surface structure, which is avoided in the minimalist approach, but the main idea is still used in transformational grammar (see Hornstein et al., 2005). LFG is a nontransformational theory that deals with the surface structure of languages and represents syntactic information in the f-structure. As explained above, the f-structure must meet the wellformedness conditions, meaning that in this framework, we assume that if the f-structures are not complete, coherent and consistent, then they are not wellformed. If we look at the f-structure that is suggested in the double-tier analysis for verbless sentences in $(30 \mathrm{~b})$ or $(35 \mathrm{~b})$, we see that they are wellformed. The null copula requires two arguments, and they are available in both f-structures.

However, this does not mean that we should not care about case markings in LFG; rather, it means that they are not central in this framework. In this paper, we assume that if the second part of a verbless sentence is a noun, pronoun, adverb or prepositional phrase, then we should use the double-tier analysis and assume that there is a covert copula. The issue of case marking appears when the second part is a noun or a pronoun because they carry a nominative case marking, as shown in the repeated two examples below:

\footnotetext{
(44) a. hūa rağul-un.

P.3SGM.NOM man.N-NOM

'He (is) a man'

b. hāda hūa.

DEM.2SGM.NOM P.3SGM.NOM

'This (is) him'
} 
In contrast, when the second part is an adverb, it may or may not carry an accusative case marking, and when the second part is a prepositional phrase, there is no case marking. In LFG, the analysis should describe the system of languages. As shown above, the problem is in the second part of the two sentences in (44) if we use the double-tier analysis. In this case, there is a difference between the covert and overt copula in that when the copula appears, the second part is in accusative case, and when it disappears, the second part is in nominative case. We suggest that the solution of this problem is in the language itself. Therefore, this paper suggests that in both cases, the second part is the object of a covert or overt copula. When the copula appears, the complement carries an accusative case marking, and when it disappears, the complement carries a nominative case marking. This assumption is not strange in MSA because objects sometimes carry a nominative case marking and subjects an accusative case marking as long as the meaning is clear (see Alansari, nd). Additionally, we assume that the difference between the case marking in both constructions is because of the semantic difference between them. As shown above, when yakun optionally appears, it makes a semantic difference; namely, it emphasizes the relationship between the subject and the complement, thus confirming the meaning of the sentence. It is clear that LFG is more flexible and able to use both assumptions in analyzing verbless sentences without serious problems.

\section{Conclusion}

This paper discusses verbless sentences in MSA and shows the analysis of this type of sentence in transformational grammar and the LFG framework. We argue that LFG is more flexible than other theories and provides a simple analysis for verbless sentences. The single-tier and the double-tier analysis are discussed in this paper, and we argue that there is no one right analysis for this phenomenon in MSA. Therefore, both analyses should be used in analyzing verbless sentences in MSA. This paper suggests that the single-tier analysis should be used when the second part of a verbless sentence is an adjective because adjectives are able to function as predicates. In contrast, if the second part of a verbless sentence is a nonadjectival word, the double-tier analysis should be used because the null copula in this analysis will be the predicate of the sentence.

\section{Acknowledgment}

This project was supported by the Deanship of Scientific Research at Prince Sattam Bin Abdulaziz University under the research project 2019/02/10213.

\section{References}

Al-Horais, N. (2006). Arabic verbless sentences: Is there a null vp? Pragmalingüistica, 14, 101-116

Alansari, E. (n.d.). muqni allabib. dar alfikr.

Alotaibi, A. S. (2018a). The Copula in Arabic: Description and Analysis. Ph. D. thesis, University of Essex.

Alotaibi, Y. H. (2014). Conditional Sentences in Modern Standard Arabic and the Taif Dialect. Ph. D. thesis, University of Essex.

Alotaibi, Y. H. (2017a). The analysis of auxiliaries in modern standard Arabic. Journal of Faculty of Language and Translation, 12(11).

Alotaibi, Y. H. (2017b). Gapping: A new lfg approach. International Journal of English Linguistics, 7(6), 188-197. https://doi.org/10.5539/ijel.v7n6p188

Alotaibi, Y. H. (2019). Depictives: An lfg approach. International Journal of English Linguistics, 9(3), 188-202. https://doi.org/10.5539/ijel.v9n3p188

Alotaibi, Y. H. A. (2018b). Shared arguments in modern standard arabic (isi). International Journal of English Linguistics, 8(1), 164-183. https://doi.org/10.5539/ijel.v8n1p164

Aoun, J. E., Choueiri, L., \& Benmamoun, E. (2010). The syntax of Arabic. Cambridge University Press. https://doi.org/10.1017/CBO9780511691775

Attia, M. (2008). A unified analysis of copula constructions in lfg. In M. Butt \& T. H. King (Eds.), Proceedings of LFG08 (pp. 89-108). CSLI Publications.

Bakir, M. J. (1979). Aspects of Clause Structure in Arabic: A Study in Word Order Variation in Literary Arabic. Ph. D. thesis, Indiana University.

Benmamoun, E. (2000). The feature structure of functional categories: A comparative study of Arabic dialects. Oxford: Oxford University Press.

Boneh, N. (2010). Perfect Constructions in Syrian Arabic. In P. C. Hoffherr \& B. Laca (Eds.), Layers of Aspect. 
Stanford, CA: CSLI Publications. Retrieved from http://www- csli.stanford.edu/publications

Bresnan, J. (2001). Lexical-Functional Syntax. Oxford: Blackwell Publishers.

Butt, M., King, T. H., Niño, M., \& Segond, F. (1999). A Grammar Writer's Cookbook. Stanford, CA.

Curnow, T. J. (2000). Towards a cross-linguistic typology of copula constructions (pp. 1-9). In Proceedings of the 1999 Conference of the Australian Linguistic society. Retrieved from http://www.als.asn.au/proceedings/als1999/curnow.pdf

Dalrymple, M. (2001). Lexical functional grammar (Vol. 42). Academic Press New York. https://doi.org/10.1163/9781849500104

Dalrymple, M., Dyvik, H., \& King, T. H. (2004). Copular complements: Closed or open (pp. 188-198). In Proceedings of the LFG04 Conference.

Dalrymple, M., Kaplan, R. M., Maxwell, III, J. T., \& Zaenen, A. (Eds.) (1995). Formal Issues in Lexical-Functional Grammar. Stanford, CA.

Dechaine, R. (1993). Predicates across categories: Towards a category-neutral syntax. Ph. D. thesis, University of Massachusetts.

Eid, M. (1991). Verbless sentences in Arabic and Hebrew. Perspectives on Arabic linguistics, 3, 31-61. https://doi.org/10.1075/cilt.80.05eid

Eisele, J. C. (1990). Aspectual Classification of Verbs in Cairene Arabic. In M. Eid \& J. Mc-Carthy (Eds.), Perspectives on Arabic Linguistics I! (Chapter Aspectual, pp. 192-233). Ben-jamins. https://doi.org/10.1075/cilt.72.12eis

Falk, Y. (2001). Lexical-functional grammar. CSLI.

Falk, Y. N. (1984). The English Auxiliary System: A Lexical-Functional Analysis. Language, 60(3), 483-509. https://doi.org/10.2307/413988

Fassi, F. A. (1993). Issues in the structure of Arabic clauses and words. Dordrecht: Kluwer. https://doi.org/10.1007/978-94-017-1986-5

Hassaan, A. (2008). alnahw alwafi. daar almaarif.

Hornstein, N., Nunes, J., \& Grohmann, K. K. (2005). Understanding minimalism. Cambridge University Press. https://doi.org/10.1017/CBO9780511840678

Jelinek, M. E. (1981). On defining categories: aux and predicate in colloquial Egyptian Arabic. Ph. D. thesis, The University of Arizona.

Kaplan, R. M., \& Bresnan, J. (1982). Lexical-Functional Grammar: A formal system for grammatical representation. In J. Bresnan (Ed.), The Mental Representation of Grammatical Relations (pp. 173-281). Cambridge, MA: The MIT Press. Reprinted in Dalrymple et al. (1995, pp. 29-130).

Kiparsky, P., \& Kiparsky, C. (1970). Fact. In M. Bierwisch \& K. E. Heidolph (Eds.), Progress in Linguistics (pp. 143-173). The Hague: Mouton de Gruyter. https://doi.org/10.1515/9783111350219.143

Li, C. N., \& Thompson, S. A. (1977). A mechanism for the development of copula morphemes. Mechanisms of syntactic change, 419-444.

Mouchaweh, L. (1986). De la syntaxe des petites propositions. Ph. D. thesis, Atelier National de Reproduction des The'ses de l'Univ. de Lille.

Nordlinger, R., \& Sadler, L. (2007). Verbless Clauses: Revealing the Structure within. In J. Grimshaw, J. Maling, C. Manning, J. Simpson, \& A. Zaenen (Eds.), Architectures, Rules and Preferences: A Festschrift for Joan Bresnan (pp. 139-162). Stanford, CA: CSLI Publications.

Postal, P. M. (1974). On Raising. Cambridge, MA: The MIT Press.

Rapoport, T. R. (1987). Copular, nominal, and small clauses: A study of Israeli Hebrew. Ph. D. thesis, Massachusetts Institute of Technology.

Rose' n, V. (1996). The LFG Architecture and "Verbless" Syntactic Constructions. In Proceedings of LFG 1996, Stanford, CA. CSLI Publications. Retrieved from http://www-csli.stanford.edu/publications

Ryding, K. (2005). A reference grammar of modern standard Arabic. Cambridge Univisity Press. https://doi.org/10.1017/CBO9780511486975 
Simpson, J. (1991). Warlpiri Morpho-Syntax: A Lexicalist Approach. Dordrecht: Kluwer Academic Publishers. https://doi.org/10.1007/978-94-011-3204-6

\section{Note}

They are called raising verbs in transformational grammar because it is assumed that the subject of the subordinate clause has been raised from the subordinate clause to the matrix clause (see Kiparsky \& Kiparsky, 1970).

\section{Copyrights}

Copyright for this article is retained by the author, with first publication rights granted to the journal.

This is an open-access article distributed under the terms and conditions of the Creative Commons Attribution license (http://creativecommons.org/licenses/by/4.0/). 